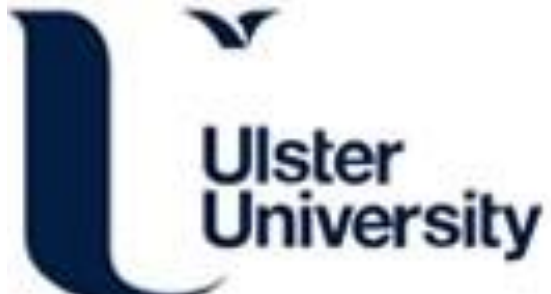

\section{Radially Grown Graphene Nanoflakes on Carbon Fibers as Reinforcing Interface for Polymer Composites}

Karakasidis, A., Ganguly, A., Tsirka, K., Paipetis, A., \& Papakonstantinou, P. (2020). Radially Grown Graphene Nanoflakes on Carbon Fibers as Reinforcing Interface for Polymer Composites. ACS Applied Nano Materials, 3(3), 2402-2413. https://doi.org/10.1021/acsanm.9b02536

Link to publication record in Ulster University Research Portal

Published in:

ACS Applied Nano Materials

Publication Status:

Published (in print/issue): 31/03/2020

DOI:

10.1021/acsanm.9b02536

Document Version

Publisher's PDF, also known as Version of record

\section{General rights}

Copyright for the publications made accessible via Ulster University's Research Portal is retained by the author(s) and / or other copyright owners and it is a condition of accessing these publications that users recognise and abide by the legal requirements associated with these rights.

\section{Take down policy}

The Research Portal is Ulster University's institutional repository that provides access to Ulster's research outputs. Every effort has been made to ensure that content in the Research Portal does not infringe any person's rights, or applicable UK laws. If you discover content in the Research Portal that you believe breaches copyright or violates any law, please contact pure-support@ulster.ac.uk. 


\title{
Radially Grown Graphene Nanoflakes on Carbon Fibers as Reinforcing Interface for Polymer Composites
}

\author{
Anastasios Karakassides, Abhijit Ganguly, Kyriaki Tsirka, Alkiviadis S. Paipetis, \\ and Pagona Papakonstantinou*
}

Cite This: https://dx.doi.org/10.1021/acsanm.9b02536

Read Online

\section{ACCESS \\ Џlll Metrics \& More \\ Article Recommendations \\ Supporting Information}

ABSTRACT: The development of nanoscale reinforcements, which can tailor the interfacial strength and impart multiple functionalities on carbon fiber reinforced polymer (CFRP) composites, remains a challenge for their largescale adoption in diverse applications ranging from aerospace to transportation and construction industries. In this work radially aligned graphene nanoflakes (GNFs), grown directly on carbon fibers ( $\mathrm{CFs}$ ) via a simple one-step microwave plasma enhanced chemical vapor deposition method, without any catalyst, were used as a novel nano-reinforcement interface. A remarkable $28 \%$ enhancement in the tensile strength of the hybrid fibers was observed via singlefiber tensile strength tests, whereas the interfacial shear strength (IFSS) increased by $101.5 \%$. Our results demonstrate that GNFs not only improve the interfacial strength between the GNFs and the epoxy resin but also enhance the in-plane mechanical strength of the CFs-a well-known problem encountered

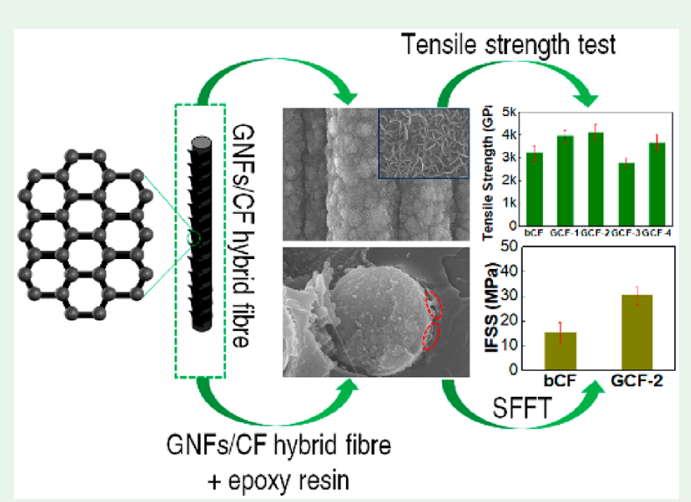
with the direct growth of carbon nanotubes on CFs. In addition, GNFs provided embedded functionality via increased electrical conductivity $(60.5 \%$ improvement for yarns and $16 \%$ for single fiber) and electrochemical capacitance ( $157 \%$ for yarns). This work indicates the potential of GNFs as an interphase for the simplified and costeffective production of stronger multifunctional CFRP composite materials.

KEYWORDS: vertical graphene nanoflakes (GNFs), tensile strength, interfacial shear strength (IFSS), electrical conductivity, electrochemical capacitance, multifunctional fibers, hierarchical structures

\section{INTRODUCTION}

Carbon fiber reinforced polymers (CFRP), made of carbon fibers (CFs) reinforcing a resin matrix, are central to the production of stronger yet lighter components for airplanes, cars, trains, ship containers, and wind turbines. The ever increasing requirements for cost efficiency and ecological policies led to the gradual migration from metallic to composite structures in these industries, as the reduction in body mass reduces fuel consumption and greenhouse emissions. The high specific in-plane mechanical properties of CFs are the cornerstone of the superior performance of CFRPs. However, this performance is significantly affected by their reduced out-of-plane properties. These shortcomings are largely governed by the interfacial strength between fibers and polymer matrix, which in its turn is governed by the specific surface area, the low surface energy, the nonpolar characteristics, and the chemical inertness of CFs. The weak interfacial bonding does not allow the effective transfer of stress from the matrix to the CFs, leading to fiber debonding and pull-out from the matrix, which deteriorate the properties of CFRPs. Therefore, an appropriately engineered interface is essential to ensure the efficient load transfer from the matrix to the reinforcements and significantly enhance the mechanical behavior of composites.

To counterbalance the poor bonding of matrix material to CFs, many surface modifications have been introduced to reinforce the interface at the macro and molecular level. These approaches include surface modification of CFs to improve the compatibility between CFs and polymer matrix, such as sizing, ${ }^{1}$ coating, ${ }^{2,3}$ oxidation, ${ }^{4}$ plasma treatments, ${ }^{5-7}$ chemical grafting, $^{8-12}$ and electrophoretic deposition. ${ }^{13-15}$ Popular efforts include the incorporation of secondary nanoscale reinforcements (e.g., graphene and carbon nanotubes) at the interface between the fiber and matrix. ${ }^{16-20}$ One particularly promising interface reinforcement route is the "roughening" of the fiber surface via direct growth of hierarchical architectures on it. A notable example of these reinforcement interphases includes the radial direct growth of carbon nanotubes (CNTs) on CFs. Because of the poor wettability of CFs in CNT growth catalyst

Received: December 19, 2019

Accepted: February 13, 2020

Published: February 13, 2020 
Scheme 1. Schematic Illustration of GNFs/CF Hybrid Fabrication

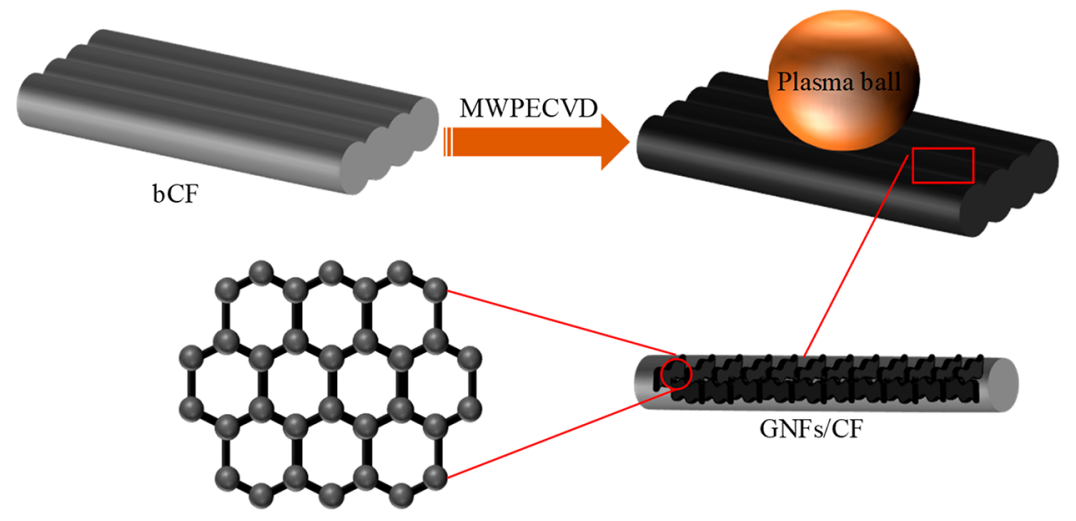

solutions, past works have employed harmful surface treatments to improve catalyst adhesion; ${ }^{21}$ with only few exceptions, ${ }^{22}$ in the reported literature, the majority of efforts have resulted in compromises of in-plane mechanical properties. $^{23,24}$ Accelerated interdiffusion of the catalyst particles on the CF surface, at the high temperatures used for the CVD growth of carbon nanostructures, was identified by several authors as the main mechanism, responsible for the encountered in-plane strength losses, ${ }^{25}$ while Steiner et al. ${ }^{26}$ claimed that thermally activated mechanochemical changes in the CF structure were mainly accountable for the reduction in CF strength.

Recent efforts to overcome these challenges include noncovalent functionalization routes to avoid direct contact of the catalyst with the carbon fabric. These methods, in conjunction with low growth temperatures, have shown to preserve the interfacial properties of the CFs. However, it is important that the fiber yarn is kept under tension during growth, which complicates the manufacturing process. ${ }^{29}$ Nevertheless, the multiple processing steps render this approach costly and not amenable to large-scale production.

A novel type of hierarchical reinforcing interface, almost unexplored so far, is that of vertically aligned, self-assembled 3D network of graphene nanoflakes (GNFs). In the literature, GNFs can also be found with other names, like carbon nanowalls, ${ }^{28}$ graphene nanowalls, ${ }^{29}$ graphitic petals, ${ }^{30}$ or graphene nanopetals. ${ }^{31}$ GNFs are multilayer systems of graphene sheets, oriented perpendicular to a substrate's surface, forming a labyrinth network like pattern. They encompass a number of important assets: (i) They can be self-assembled on any type of surface without use of any metal catalyst. Because no catalyst is required for the growth of GNFs, it is expected that the in-plane strength of the fibers can be maintained, provided that the CFs are not subjected to high temperatures for long durations. Additionally, the elimination of catalyst makes the manufacturing process much easier compared to those used for the growth of CNTs. (ii) The distribution of load-bearing graphene sheets is not uniform but rather creates a gradient of layers, with the number of layers being highest at the base and gradually lower at the top. ${ }^{32-34}$ Such a graded interface emulates biological systems which rarely exhibit discrete boundaries between two systems of vastly different mechanical properties. This biomimetic graded interface $^{35}$ could effectively transfer load between the matrix and the fibers and reduce stress concentrations. (iii) The hybrid structure exhibits high porosity and robustness, which are beneficial for ensuring efficient infiltration of resin. Because of their robust structure, GNFs are more likely to retain their shape under the action of forces generated by the resin infusion process, in contrast to CNTs. (vi) Finally, the direct contact of GNFs and CF at the GNFs/CF interface minimizes Ohmic contact resistance, facilitating efficient out-of-plane electrical and thermal transport, ${ }^{30,31}$ hence giving rise to multifunctional capabilities.

GNFs have received significant attention over recent years due to their conductive, porous morphology, and electron rich edges, which make them well suited for a variety of fields including electron field emission, ${ }^{36}$ blackbody antireflective coatings, ${ }^{37}$ electrodes for sensing, ${ }^{38-40}$ and energy conversion and storage (electrodes for fuel cells, ${ }^{41,42}$ batteries supercapacitors, $^{43-46}$ and solar cells $\left.{ }^{47,48}\right)$. However, their use as a nano-reinforcement interface is an almost unexplored terrain with only limited work reported so far ${ }^{49-51}$ on radio-frequency plasma enhanced chemical vapor deposited (rf-PECVD) GNFs on CFs. Furthermore, there are no studies that combine electrical, electrochemical, and mechanical properties to assess the potential for multifunctionality of the hybrid GNFs/CF fibers on structural composite applications.

In this work, GNFs grown by microwave plasma enhanced CVD (mw-PECVD) are used as a novel and quick one step means to reinforce the interface of CFRP. To the authors' knowledge, no other research groups have investigated the tensile and interfacial strength of CF with directly grown GNFs synthesized by mw-PECVD composites (Scheme 1). By tailoring the synthesis parameters, so that minimal thermal loading is imposed on the CFs, the tensile strength of the original CFs was enhanced in the GNFs/CF hybrid, which is first reported here. Additionally, with the GNF growth, an increase in interfacial strength with the epoxy matrix was observed and is hypothesized to arise from both an increased surface roughness and a robust adhesion to the carbon fiber surface, achieved by the energetic nature of the plasma deposition. For the first time, the multifunctionality of GNFs on CFs is demonstrated by showing interfacial reinforcement and enhanced electrical and electrochemical properties.

\section{MATERIALS AND METHODS}

2.1. Direct Growth of GNFs on Carbon Fibers by Microwave Plasma Enhanced CVD. The synthesis of graphene nanoflakes (GNFs) was conducted in a $1.5 \mathrm{~K} \mathrm{~W}, 2.45 \mathrm{GHz}$, SEKI Technotron mw-PECVD system with $\mathrm{N}_{2}$ and $\mathrm{CH}_{4}$ as the primary feed gases (Supporting Information section S2 and Figure S1). The CFs yarns were placed on a $62 \mathrm{~mm}$ Mo holder. After pumping the chamber down less than $6 \times 10^{-3}$ Torr, we introduced $\mathrm{N}_{2}(30 \mathrm{sccm})$ to achieve the desired total pressure of 15 Torr. At that point, the temperature of 
the holder was increased by using rf-inductive heating. This type of heating allows high ramp rates of about $55-60{ }^{\circ} \mathrm{C} / \mathrm{min}$. When the desired temperature was reached, $\mathrm{CH}_{4}(20 \mathrm{sccm})$ was introduced inside the chamber and the striking process of the plasma started. Three different microwave powers were selected: 500, 800, and 950 $\mathrm{W}$. The total time of the procedure was kept at $5 \mathrm{~min}$. Prior to deposition the samples were etched with $\mathrm{N}_{2}$ plasma for $2 \mathrm{~min}$. The GNFs growth time was kept at $3 \mathrm{~min}$. The substrate temperature was kept at $300-600{ }^{\circ} \mathrm{C}$. After the deposition the samples were cooled in a constant $\mathrm{N}_{2}$ flow of $50 \mathrm{sccm}$. Other details of materials and methods are described in the Supporting Information.

2.2. Mechanical Characterization of Hybrid Fibers via Single Carbon Fiber Tensile Strength Measurements. Tensile tests on single carbon fibers were performed on a Deben Ltd. Microtester (Figure S7) with a load cell $5 \mathrm{~N}$. The Young's modulus, ultimate strength, and failure strain were determined according to ASTM C 1557-03. ${ }^{52}$ The motor speed was selected at $0.1 \mathrm{~mm} / \mathrm{min}$, and the amount of time between each data acquisition was $100 \mathrm{~ms}$. The Microtester was controlled by the Deben MICROTEST software version 6.3.30. The tensile strength of the fiber was calculated as follows:

$$
T=\frac{F}{A}
$$

where $T(\mathrm{~Pa})$ is the tensile strength, $F(\mathrm{~N})$ is the force to failure, and $A\left(\mathrm{~m}^{2}\right)$ is the fiber's cross-sectional area at fracture plane (normal to fiber axis). The fiber's cross-sectional area $(A)$ was calculated as follows:

$$
A=\pi \frac{d^{2}}{4}
$$

where $d(\mathrm{~m})$ is mean diameter of coated fiber. The strain, $\varepsilon$, of the fiber was calculated by

$$
\varepsilon=\frac{\Delta l}{l_{0}}
$$

where $\Delta l(\mathrm{~mm})$ is the elongation of the gage length and $l_{0}(\mathrm{~mm})$ is the gage length. The Young's modulus of the fiber was calculated from the slope of the linear region of the stress-strain curves.

2.3. Mechanical Characterization of Hybrid Fibers via Single-Fiber Fragmentation Measurement. The interfacial shear strengths (IFSS) of bare (bCF) and coated carbon fiber GCF-2 with epoxy matrix were also evaluated by single fiber fragmentation tests (SFFT). Dog-bone-shaped model-composite specimens consisting of a single fiber aligned carefully in the middle the resin were prepared and tested. A silicone rubber mold (Figure S10) was used for the preparation of the specimens. The fibers were stabilized on the pins of the mold with the aid of a superglue; then the mold was filled with a two-part epoxy resin system, and the specimens were cured for $2 \mathrm{~h}$ at $60^{\circ} \mathrm{C}$. After curing, the specimens were left to cool to room temperature before removing them from the mold. Subsequently, a postcuring cycle was performed at $120^{\circ} \mathrm{C}$ for $1.5 \mathrm{~h}$, following cooling to ambient conditions. Subsequently, their surface was subjected to sequential sanding with $800,1000,1200,2400$, and 4000 grit sandpapers and polishing with a $3 \mu \mathrm{m}$ diamond paste. The specimens were ready for microscopic characterization when the fiber was at $\sim 0.2 \mathrm{~mm}$ from their surface.

During the fragmentation test, these specimens were loaded to tension, with a loading rate of $0.1 \mathrm{~mm} / \mathrm{min}$, up to $\sim 6 \%$ strain by using a custom-made horizontal tensile testing stage, which was placed under the optical microscope (Figure S11). All the coupons were loaded at incremental strain levels until saturation. Each experiment was paused every $0.2 \%$ of applied strain, and the fragments of the CFs were measured from the birefringence patterns via polarized optical microscopy. Five samples were tested for each category, and each fiber diameter was evaluated before testing by averaging at least 10 optical measurements along its active length.

During SFFT testing of a model-composite specimen, the stress is transferred by the resin to the CF through the interfacial region. As the externally applied load increases, the CF breaks into increasingly smaller fragments at locations, where the $\mathrm{CF}$ axial stress reaches its tensile strength. This fragmentation process is continued by further stressing of the specimens until reaching saturation whereby all the CF fragments are too small to reach their tensile strength for further fragmentations to occur. The mean fragment length, $l_{\mathrm{f}}$, is the average fragment length achieved at the saturation stage and is used for the calculation of the critical length, $l_{\mathcal{c}}$ through the equation $l_{c}=(4 / 3) l_{\mathrm{f}}$. Then, the IFSS $(\tau)$ can be calculated by using the Kelly and Tyson model: ${ }^{53}$

$$
\tau=\left(\sigma_{\mathrm{f}} / 2\right)\left(d / l_{\mathrm{c}}\right)
$$

where $\sigma_{\mathrm{f}}$ is the tensile strength of the fiber at the critical length $l_{\mathrm{c}}$ and $d$ is the diameter of the fiber.

For the calculation of the strengths of the CF and the GCF-2 at the small values of the critical lengths observed during SFFT a Weibull analysis was performed using the Weibull distribution function:

$$
P=1-\exp \left[-L\left(\frac{\sigma}{\sigma_{0}}\right)^{m}\right]
$$

where $\sigma$ is the applied stress, $\sigma_{0}$ is a scale parameter, and $m$ is the dimensionless Weibull modulus.

By rewriting this equation in the linear form, we can then plot the $\ln (-\ln (1-P))$ against $\ln (\sigma)$; then the Weibull modulus was calculated from the slope of the curve while the scale parameter was estimated from the value of the intercept through the equation

$$
\sigma_{0}=\mathrm{e}^{-\mathrm{intercept} / m}
$$

The probability of failure was calculated in this study by the maximum likelihood estimator $(P=\sigma-0.5 / n)$, where $\sigma$ is the failure stress of each CF and $n$ is the number of tested CFs. After evaluation of the Weibull shape and scale parameters, the fiber strength at the short critical lengths observed during SFFT was calculated according to the following equation: ${ }^{54}$

$$
\langle\sigma\rangle=\sigma_{0} L^{-1 / m} \Gamma(1+1 / m)
$$

where $\Gamma$ is the gamma function.

The Weibull plots and results derived from this analysis are presented in Figure S12 and Table S3.

2.4. Electrical Conductivity Measurements. Electrical conductivity measurements were performed on the GNFs/CF yarns and single fibers via a Keithley $2611 \mathrm{~B}$ system source meter utilizing two probes. Conductive silver paint was placed at the edges of the yarn, and copper tape was placed above the silver paint providing in this way a more uniform and conductive contact between the crocodile clips and the carbon fiber yarn. For the calculation of the electrical conductivity the following equation was used:

$$
\sigma=G \frac{L}{A}
$$

where $\sigma$ is the electrical conductivity $(\mathrm{S} / \mathrm{cm}), L$ is the length between the two contacts, $G$ is the conductance $(S)$, and $A$ is the crosssectional area $\left(\mathrm{cm}^{2}\right)$.

2.5. Electrochemical Characterization. Electrochemical characterizations were performed on an Autolab PGSTAT/FRA system, employing a typical three-electrode configuration with a platinum wire ( $\mathrm{Pt}, \mathrm{CHI}$. Instrument, Inc.) as a counter electrode (CE) and $\mathrm{Ag} / \mathrm{AgCl}$ ( $3 \mathrm{M} \mathrm{KCl}, \mathrm{CHI}$. Instrument, Inc.) as a reference electrode (RE). The working electrode (WE) was fabricated by paint-drying Agconducting paste at one end of the bare (bCFs) or graphene nanoflake-coated carbon fiber yarn (GCF) and wrapping it with $\mathrm{Cu}$ adhesive tape to ensure stable electrical contact.

Capacitance measurements were made in fresh $1.0 \mathrm{M} \mathrm{H}_{2} \mathrm{SO}_{4}(\mathrm{pH}$ 0) and 1.0 $\mathrm{M} \mathrm{NaClO}_{4}(\mathrm{pH} 7.4$ ) electrolyte solutions by employing cyclic voltammetry $(\mathrm{CV})$, recorded in a three-electrode configuration. Prior to the actual capacitance measurement, every $\mathrm{CF}$ electrode was subjected to continuous potential cycling at a rate of $10 \mathrm{mV} / \mathrm{s}$ until stable CVs were achieved. Every CF electrode was first subjected to 

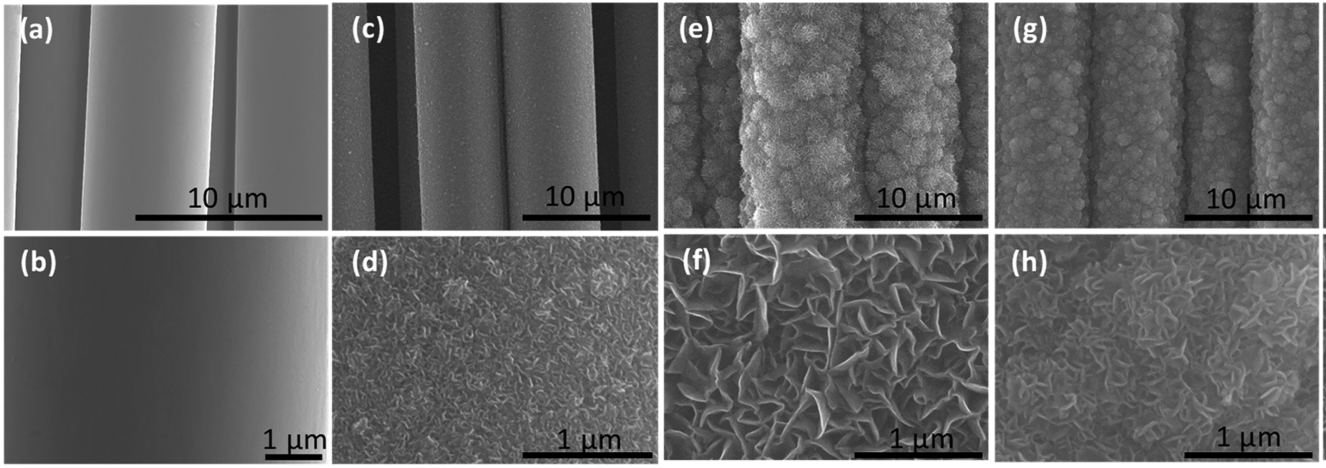

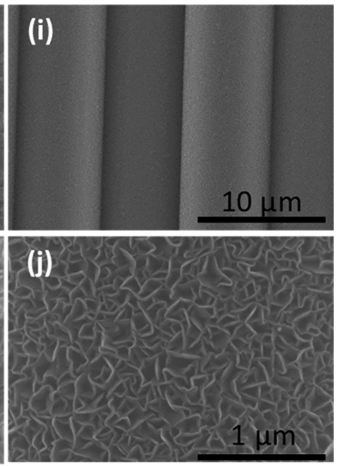

Figure 1. Observations on the morphology of the grown GNFs on the CFs: SEM photographs of (a, b) bare (bCF) and GNFs/CF hybrid yarns: (c, d) GCF-1 (500 W at $\left.600{ }^{\circ} \mathrm{C}\right),(\mathrm{e}, \mathrm{f}) \mathrm{GCF}-2\left(800 \mathrm{~W}\right.$ at $\left.600{ }^{\circ} \mathrm{C}\right),(\mathrm{g}, \mathrm{h}) \mathrm{GCF}-3\left(950 \mathrm{~W}\right.$ at $\left.600{ }^{\circ} \mathrm{C}\right)$, and $(\mathrm{i}, \mathrm{j}) \mathrm{GCF}-4\left(800 \mathrm{~W}\right.$ at $\left.300{ }^{\circ} \mathrm{C}\right)$.

the measurement of capacitance, via scan rate dependent $\mathrm{CV}$ study, in $1 \mathrm{M} \mathrm{H}_{2} \mathrm{SO}_{4}$ solution, followed by the same test in $1 \mathrm{M} \mathrm{NaClO}_{4}$ solution. Finally, the same electrode was subjected to a redox activity study (via $\mathrm{CV}$ and $\mathrm{EIS}$ ) in $5 \mathrm{mM} \mathrm{K}{ }_{4} \mathrm{Fe}(\mathrm{CN})_{6}$ of $0.1 \mathrm{M} \mathrm{KCl}$ solution. Electrochemical impedance spectroscopy (EIS) was performed in the frequency range from $100 \mathrm{kHz}$ to $0.01 \mathrm{~Hz}$ with an $\mathrm{AC}$ perturbation amplitude of $10 \mathrm{mV}$. Notably, all electrodes were carefully and thoroughly washed in DI water and completely dried before each step.

The highly concentrated sodium perchlorate $\left(\mathrm{NaClO}_{4}\right)$ aqueous solution was chosen as a neutral electrolyte because of its extremely high solubility in water and extremely slow evaporation rate due to the strong hydration of $\mathrm{Na}^{+}$and $\mathrm{ClO}_{4}{ }^{-}$ions. As a result, it exhibited a wider operating voltage window of $1.15 \mathrm{~V}(-0.15$ to $+1.0 \mathrm{~V})$ compared to $1.0 \mathrm{~V}(0.0$ to $+1.0 \mathrm{~V})$ observed in $1.0 \mathrm{M} \mathrm{H}_{2} \mathrm{SO}_{4}$ electrolyte. ${ }^{55}$

2.5.1. Analysis of Capacitance Measurements. The areal specific capacitance $\left(C_{\mathrm{sp}}\right)$, derived from cyclic voltammetry, in a threeelectrode configuration, was calculated by integrating the area under the positive $\left(Q_{i}^{+}\right)$and negative $\left(Q_{i}^{-}\right)$sweep of the $C V$ cycle and by using eq 9 :

$$
C_{\mathrm{sp}}=\frac{Q_{i}^{+}+Q_{i}^{-}}{2 \times \Delta U \times \nu \times A}
$$

where $\Delta U$ is the potential window $(\mathrm{V})$ difference between lower and upper voltage limits, $\nu$ is the potential scan rate, and $A$ is the geometric area of the working electrode (WE) immersed into the solution during measurement.

The energy or Coulombic efficiency $\left(\eta_{\mathrm{E}}\right)$ was calculated via the expression

$$
\eta_{\mathrm{E}}=\frac{Q_{i}^{-}}{Q_{i}^{+}} \times 100 \%
$$

where $Q_{i}^{+}$and $Q_{i}^{-}$are charges stored and released during the charging (positive) and discharging (negative) phases of the CV cycle, respectively.

2.5.2. Analysis of Redox Activity Study. The linear relationship of the redox peak currents $\left(I_{\mathrm{p}}\right)$ with the square root of scan rates $\left(\nu^{1 / 2}\right)$ of potential suggests diffusion-controlled mass transport, following the Randles-Sevcik equation

$$
I_{\mathrm{p}}=\left(2.69 \times 10^{5}\right) \times n^{3 / 2} \times \mathrm{ESA} \times D^{1 / 2} \times C \times \nu^{1 / 2}
$$

where $n$ is the number of electrons participating in the redox reaction $\left(1\right.$ for $\left.\mathrm{Fe}(\mathrm{CN})_{6}{ }^{3-/ 4-}\right) . D$ and $C$ represent the diffusion coefficient $(7.6$ $\left.\times 10^{-6} \mathrm{~cm}^{2} / \mathrm{s}\right)$ and concentration $\left(5 \times 10^{-6} \mathrm{~mol} / \mathrm{cm}^{3}\right)$ of $\mathrm{K}_{4} \mathrm{Fe}(\mathrm{CN})_{6}$ in solution. ESA is the only parameter of the working electrode material, representing the electroactive surface area of electrode $\left(\mathrm{cm}^{2}\right)$.

The electrocatalytic efficiency for redox activity of the working electrode material was estimated by

$$
\eta_{\mathrm{SA}}=\left(\frac{\mathrm{ESA}}{\mathrm{GA}}\right) \times 100 \%
$$

where ESA and GA are electroactive and geometric surface electrode areas $\left(\mathrm{cm}^{2}\right)$, respectively. The ESA value was estimated from the linear fitting of $I_{\mathrm{p}}$ vs $\nu^{1 / 2}$ plot using eq 11 .

\section{RESULTS AND DISCUSSION}

The growth of graphene nanoflakes (GNFs) was performed in a mw-PECVD system with a mixture of gases of $60 \%$ nitrogen in methane. The GNFs were grown as a function of different microwave powers between 500 and $950 \mathrm{~W}$ at two different growth temperatures of 300 and $600{ }^{\circ} \mathrm{C}$. In the following discussion GCF-1 denotes the GNFs/CF hybrid fibers fabricated at a growth temperature of $600{ }^{\circ} \mathrm{C}$ and microwave power of $500 \mathrm{~W}\left(600{ }^{\circ} \mathrm{C}\right.$ at $\left.500 \mathrm{~W}\right)$. Similarly, GCF-2 is fabricated at $600{ }^{\circ} \mathrm{C}$ and $800 \mathrm{~W}\left(600{ }^{\circ} \mathrm{C}\right.$ at $\left.800 \mathrm{~W}\right), \mathrm{GCF}-3$ is fabricated at $600{ }^{\circ} \mathrm{C}$ and $950 \mathrm{~W}\left(600^{\circ} \mathrm{C}\right.$ at $\left.950 \mathrm{~W}\right)$, and GCF4 is fabricated at $300{ }^{\circ} \mathrm{C}$ and $800 \mathrm{~W}\left(300{ }^{\circ} \mathrm{C}\right.$ at $\left.800 \mathrm{~W}\right)$. The effect of GNFs on the mechanical performance of CFs was examined through single carbon fiber tensile strength tests, whereas interfacial shear strength (IFSS) was measured by single-fiber fragmentation tests (SFFT). The electrical conductivity was evaluated through a two-probe method with applied voltage in the range $1-10 \mathrm{mV}$ on both single-fiber and yarns of CFs. Also, the capacitance of the CF yarns was measured in two different electrolytes, $1 \mathrm{M} \mathrm{H}_{2} \mathrm{SO}_{4}$ (acidic, $\mathrm{pH}$ 0 ) and $\mathrm{NaClO}_{4}$ (neutral, $\mathrm{pH}$ 7.4) solutions, through electrochemical tests. The properties of coated CFs were benchmarked against those of as-purchased bare carbon fibers (bCFs).

3.1. SEM Observations of GNFs/CF Hybrid Yarns. The morphology of the GNFs on carbon yarns was characterized by field emission scanning electron microscopy (SEM, Figure 1). Surprisingly, it was found that at the low growth temperature of $300{ }^{\circ} \mathrm{C}$ (GCF-4) the nanoflakes were uniformly radially erected from the CFs surface (Figures 1i,j), whereas at the higher temperature of $600{ }^{\circ} \mathrm{C}$ (GCF-2, Figures 1e,f) and higher plasma power of $950 \mathrm{~W}$ (GCF-3 Figures 1g,h), the nanoflakes were assembled in a spherule-like morphology with a diameter of approximately $0.5-2 \mu \mathrm{m}$. Similar spherule-like morphology was observed on as-purchased unsized CF yarns (12K CF yarn from Goodfellow, C 005722) under identical deposition conditions, indicating that their formation is not related to the sizing. Figure S5 provides lower and higher magnification images of spherules' formation on the unsized carbon fibers. They seemingly are made of a network of interconnected GNFs of slightly different heights, giving rise to 
the distinctive spherule-like morphology. The GNF spherules are coalesced into a continuous coating covering the $\mathrm{CF}$ surface. Their growth most probably is related to increased nucleation sites on both the initial and subsequent growth stages, at high power conditions (800-950 W). In the case of GCF-1 (500 W at $600{ }^{\circ} \mathrm{C}$ ), although spherules were distributed throughout the carbon surface, they were not vividly apparent due to their small size (Figures 1c,d). The highest growth rate was observed for GCF-2 $(\sim 1.10 \mu \mathrm{m}$ thick $)$ when compared to other hybrids (GCF-1: $\sim 280 \mathrm{~nm}$; GCF-3: $\sim 315 \mathrm{~nm}$; and GCF-4: $\sim 65 \mathrm{~nm}$ ). At the same time the length of graphene flakes in GCF-2 sample (Figures 1f) was the largest among the four hybrids (Figures $1 \mathrm{~d}, \mathrm{f}, \mathrm{h}, \mathrm{j}$ ), providing an increased amount of gaps between the flakes, which corroborates with the lowest $I_{\mathrm{D}} / I_{\mathrm{G}}$ ratio $(=1.23)$ observed in the Raman results (Figure $2 \mathrm{~b}$ ). Similarly, a good agreement
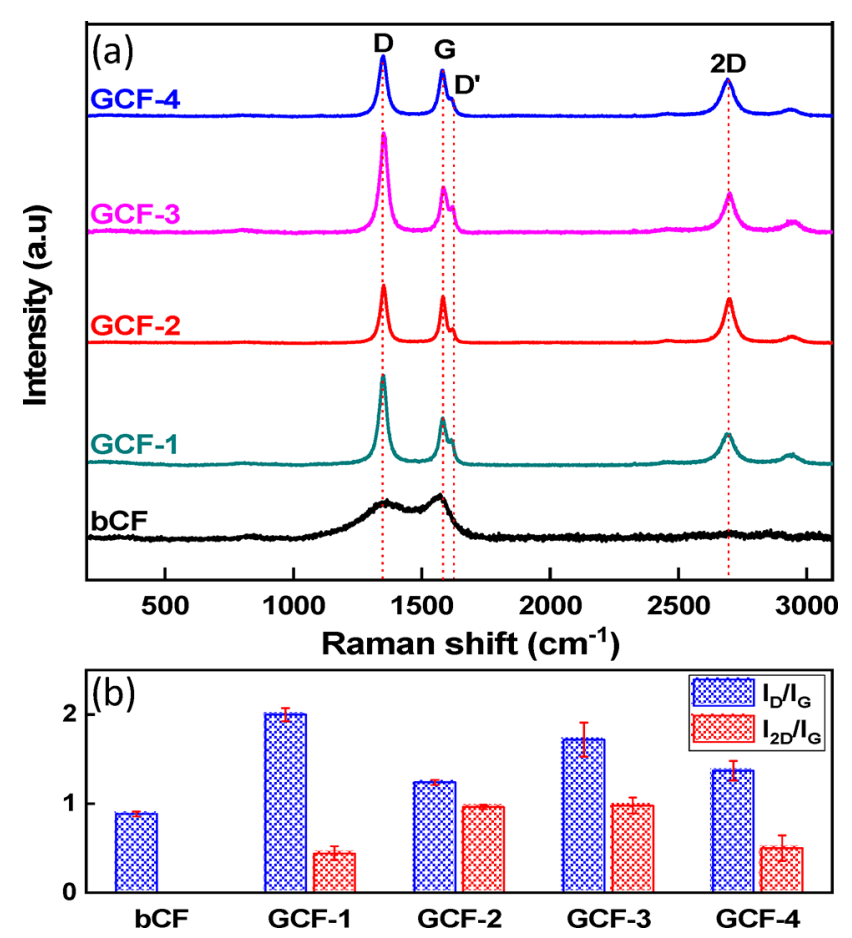

Figure 2. Raman characterization of graphene nanoflakes (GNFs) on carbon fiber (CFs) yarns: (a) Raman spectra of a bare (bCF) and GNFs/CF hybrids, denoted as GCF-1 (500 W at $\left.600{ }^{\circ} \mathrm{C}\right)$, GCF-2 $\left(800 \mathrm{~W}\right.$ at $\left.600{ }^{\circ} \mathrm{C}\right), \mathrm{GCF}-3\left(950 \mathrm{~W}\right.$ at $\left.600{ }^{\circ} \mathrm{C}\right)$, and GCF-4 $(800 \mathrm{~W}$ at $300{ }^{\circ} \mathrm{C}$ ). (b) $I_{\mathrm{D}} / I_{\mathrm{G}}$ and $I_{2 \mathrm{D}} / I_{\mathrm{G}}$ intensity ratios measured at the center of a $40 \mathrm{~mm}$ yarn. Error bars represent standard deviation from at least 20 independent measurements.

was observed between the graphene network density and the $I_{\mathrm{D}} / I_{\mathrm{G}}$ ratio. The GCF-3 $\left(950 \mathrm{~W}\right.$ at $600{ }^{\circ} \mathrm{C}$ ) demonstrated a higher network density than GCF-2, accompanied by a higher $I_{\mathrm{D}} / I_{\mathrm{G}}$ ratio 1.72 . The GCF- $1\left(500 \mathrm{~W}\right.$ at $\left.600{ }^{\circ} \mathrm{C}\right)$ exhibited the highest network density, which was reflected by the highest $I_{\mathrm{D}} /$ $I_{\mathrm{G}}$ ratio of 2.00 .

3.2. Raman Characterization of GNFs/CF Hybrid Single Fibers and Yarns. Raman characterization was performed on yarns to assess the quality and uniformity of GNFs coating on the CF surface (Figures S3 and S4, Table S2). All the spectra (Figure 2a) contained prominent vibrational modes (Table S1) near 1346, 1580, and 2691 $\mathrm{cm}^{-1}$ that correspond to the $\mathrm{D}, \mathrm{G}$, and the $2 \mathrm{D}$ bands, respectively. ${ }^{56-58}$ The $\mathrm{D}$ band is due to the presence of defects such as distortion, vacancies, and strain in graphitic networks arising from finite crystallite size and is associated with transverse optical (TO) vibrations near the $\mathrm{K}$ point. The $\mathrm{G}$ band is representative of $\mathrm{sp}^{2}$ bonding and originates from firstorder Raman scattering. The $2 \mathrm{D}$ band results from a doubleresonance Raman process.

The knee in the $G$ band $\left(D^{\prime}\right)$ is a band indicative of finite graphite crystals and graphene edges. Both the appearances of sharp $\mathrm{D}$ and distinctive $\mathrm{D}^{\prime}$ peaks are characteristic signatures of graphene nanoflakes and are associated with the prevalence of graphene edge defects. ${ }^{56}$

As the microwave power increases from 500 to $950 \mathrm{~W}$, a blue-shift on the $\mathrm{D}, \mathrm{D}^{\prime}$, and $2 \mathrm{D}$ bands, normalized to the $\mathrm{G}$ band position, can be observed in Figure S2 and Table S1, demonstrating that the plasma power is playing a crucial role to the quality of the produced GNFs. This upshift could be related to the oxygen induced hole doping of graphene sheets ${ }^{57}$ since oxygen radicals are expected to be more dominant at higher plasma powers. Alternatively, this blue-shift of the 2D band ${ }^{58}$ could also be attributed to the increased number of graphene layers expected at higher plasma powers.

The intensity ratio of the $\mathrm{D}$ band to the $\mathrm{G}$ band $\left(I_{\mathrm{D}} / I_{\mathrm{G}}\right)$ is commonly used to evaluate crystalline quality of graphitic structures and is ideally zero for highly ordered pyrolytic graphite. ${ }^{59}$ The lowest $I_{\mathrm{D}} / I_{\mathrm{G}}$ ratio of 1.23 observed for GCF-2 $\left(800 \mathrm{~W}\right.$ at $600{ }^{\circ} \mathrm{C}$ ) (Figure $2 \mathrm{~b}$ ) indicates the lowest amount of defects and correlates well with the lower density of the nanoflakes. Notably, GCF-2 displayed the lowest values of standard errors for $I_{\mathrm{D}} / I_{\mathrm{G}}$ illustrating a uniform GNF coating. A high $I_{2 \mathrm{D}} / I_{\mathrm{G}}$ ratio greater than or equal to 2 is indicative of a single-layer graphene, whereas lower values are associated with multilayer graphene. ${ }^{60,61}$ Hence, the low $I_{2 \mathrm{D}} / I_{\mathrm{G}}$ ratio values observed for all hybrids $(<1)$ reveal a large number of graphene layers in the nanoflakes.

3.3. Single-Fiber Tensile Strength Measurement of GNFs/CF Hybrids. Single-fiber tensile strength tests were performed to examine the effect of the grown GNFs on the inplane mechanical properties of the CFs. The gauge length (Figure S8) for every specimen was selected at $20 \mathrm{~mm}$. The tensile strength values were calculated via eq 1 , while the corresponding Young's modulus values were estimated from the slope of the linear region of the stress-strain curve (Figure S9 and Table S3). The tensile strength of bCF was estimated as $3.2 \pm 0.32 \mathrm{GPa}$. At microwave powers of 500 and $800 \mathrm{~W}$ a significant increase up to $28 \%$ was observed on the tensile strength of the GNFs/CF hybrid fibers ((3.6-4.1) \pm 0.35 $\mathrm{GPa}$ ) (Figure 3a), while the Young's modulus values (Figure 3b) were similar for all samples when compared to bCF. It can be postulated that at microwave powers $\leq 800 \mathrm{~W}$ the induced thermal loading on CFs is not sufficiently high to inflict detrimental effects to the mechanical integrity of them; however, it is adequate for the self-assembly of graphene crystals that can restrict crack propagation and hence be a source of increased tensile strength. GCF-2 (800 W at $\left.600{ }^{\circ} \mathrm{C}\right)$ displayed the highest tensile strength, and this can be attributed to the high crystalline quality of GNFs as well as to the good uniformity that the coating presented along the fiber length. Subjecting the fiber to intense plasmas (GCF-3 $\left(950 \mathrm{~W}\right.$ at $\left.600{ }^{\circ} \mathrm{C}\right)$ ) was found to slightly reduce the tensile strength value $(2.8 \pm 0.23)$ due to higher temperatures developed by the high-power plasmas. It should also be noted that the whole mw-PECVD process took place within only 5 min ( 2 min etching and $3 \mathrm{~min}$ deposition), and the targeted 

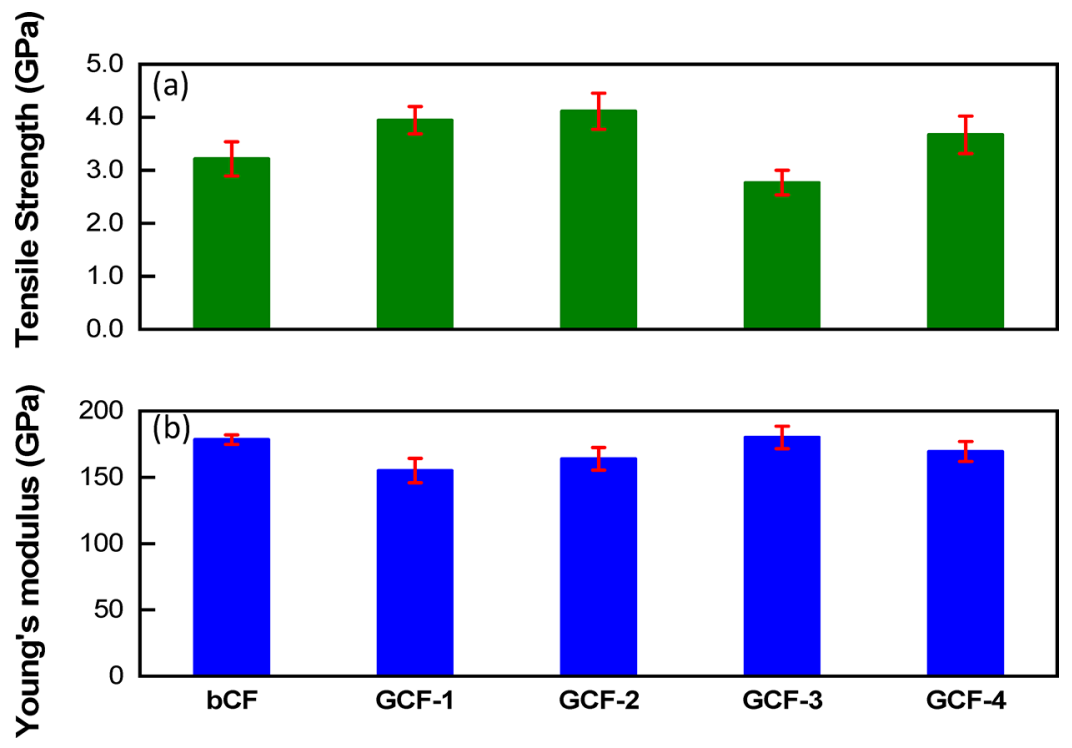

Figure 3. Single-fiber tensile strength test: (a) tensile strength and (b) Young's modulus of bare (bCF) and GNFs/CF hybrid single fibers: GCF-1 $\left(500 \mathrm{~W}\right.$ at $\left.600{ }^{\circ} \mathrm{C}\right)$, GCF-2 $\left(800 \mathrm{~W}\right.$ at $\left.600{ }^{\circ} \mathrm{C}\right)$, GCF-3 $\left(950 \mathrm{~W}\right.$ at $\left.600{ }^{\circ} \mathrm{C}\right)$, and GCF-4 $\left(800 \mathrm{~W}\right.$ at $\left.300{ }^{\circ} \mathrm{C}\right)$. Error bars represent standard deviation from at least 20 independent measurements.

temperatures were attained within $<10 \mathrm{~min}$. This is in contrast to rf-PECVD process for the growth of GNFs ${ }^{62-64}$ or thermal CVD process for the growth of $\mathrm{CNTs}^{65,66}$ where large ramping times are required for achieving the external targeted temperature and substantially longer growth durations (30-60 $\mathrm{min}$ ) are needed to achieve the desired coating thickness, both of which may impose a substantial thermal loading to the CFs and hence induce a decrease in the plane mechanical performance of the fibers. This hypothesis is supported by two recent works, ${ }^{50,51}$ where a decrease up to $19 \%$ was observed on rf-PECVD GNF/CF hybrids compared to aspurchased sized CFs. In addition to considerably reduced thermal loading, another important factor that contributed to the enhanced tensile strength in our work is the elimination of harmful chemical treatments that were conducted at past works $^{21}$ to achieve better adhesion between the catalyst and the CF surface, necessary for CNT growth. However, it is worth noting that recent efforts to overcome these challenges, including thickness control of the catalyst coating 22 and reduction of interaction time between the CFs and the catalyst, ${ }^{67}$ led to enhancement of the tensile strength up to $14 \%$. Here, GNFs were self-assembled directly on as-purchased CFs without any prior chemical treatments, since no catalyst is required for their growth. The enhancement obtained in our work is remarkably higher than those reported for CNTs (up to $14 \%)^{22,67}$ or non- carbon-modified CFs such as $\mathrm{ZnO}$ nanowire coatings on CFs $(0.2 \%){ }^{68}$

Both the modulus and strength of the GNF/CF hybrid fibers are mainly governed by the properties of the CFs. The high modulus of carbon fibers originates from the high crystallinity and the well alignment of crystals in the fiber direction. As a result, the growth of GNFs does not affect these bulk characteristics of the carbon fiber. ${ }^{69,70}$ However, the strength of the CF is affected primarily by the defects and crystalline morphologies in fibers.

Three main factors, we hypothesize, contribute to the increased tensile strength. First, the intrinsic defects on the CF surfaces are repaired during the initial stages of microwave -PECVD GNF growth process. Second, the initial graphitic layers formed at carbon fiber/GNF interface provide resistance to crack propagation by offering a longer load-carrying pathway for the cracks to propagate. Third, the strong adhesion of the CF with the interconnected 3D-GNF crystal network possessing a gradient morphology reduces interfacial stress concentrations and improves load transfer between the rigid $\mathrm{CF}$ and the hierarchical structure.

For carbon fibers the existence of surface flaws is considered a critical determinant of fiber tensile strength. ${ }^{71,72}$ The increase of $28 \%$ indicates that the growth of GNFs does not introduce defects on the fiber but in fact serves to heal any defects present on CF, leading to the enhancement of tensile strength. This healing process is connected with the growth mechanism of GNFs. Previous studies ${ }^{73,74}$ revealed that the growth of vertical graphene nanoflakes starts with the formation of a buffer layer consisting of amorphous carbon and graphitic layers parallel to the substrate surface. Lattice and thermal mismatches between the substrate and the graphitic layers cause the creation of upward curling graphitic edges, which act as nucleation sites for the vertical graphene growth. GNFs continue to grow in the vertical direction by the attachment of a high number of carbon species at the active edges. The GNFs have tapered structures, with a few graphene layers at the top (Figure S6) and progressively more layers toward the bottom.

The initial stage of growth helped to heal defects or flaws at the fiber surface, thereby reducing premature failure at stress concentration points. The high energetic nature of the plasma process offers the opportunity to diffuse into any voids and cracks on the CF surface, providing a reinforcement effect. Additionally, the initial graphitic crystals formed parallel to the CF surface help to restrict crack propagation. ${ }^{22}$ It is also assumed that, similar to biological materials, ${ }^{35}$ the gradient thickness of graphene layers in the flakes reduces the stress concentration and consequently enhances the energy dissipation.

To demonstrate the strong bonding between the CF and the directly grown GNFs, a knife adhesion test was performed to remove the GNFs. Figures $4 a$ and $4 b$ show the CF's surface after mechanically scraping the GNFs with the help of a high- 


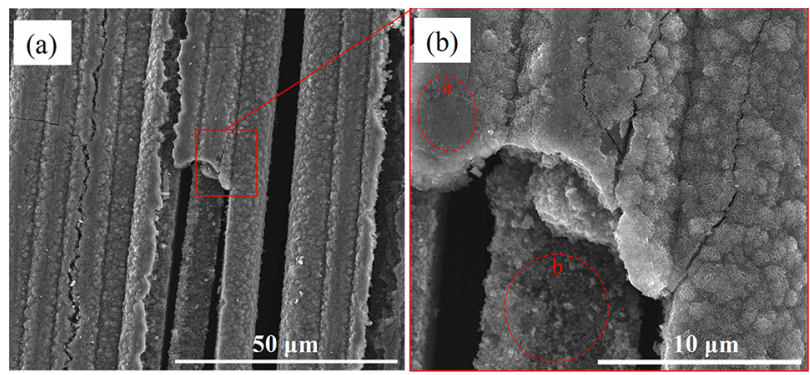

Figure 4. Adhesion tests on the grown GNFs. (a, b) Removal of the GFNs with a blade.

precision surgical blade. The SEM observations revealed that the majority of the GNF coating remained unaffected, demonstrating a strong adhesion between the CF and the GNFs. Two regions (Figure 4, regions a and $b$ ) can be readily identified from the SEM analysis. In region a, the upper GNFs were compressed or removed by the scraping process whereas in region $\mathrm{b}$ the top surface coating was removed, with $\mathrm{a}$ substantial amount of GNFs remaining adherent to CF. Overall adhesion tests demonstrated very good bonding characteristics between the GNFs and the CFs, indicating a strong GNFs/CF interface capable to promote increased tensile strength.

3.4. Interfacial Shear Strength (IFSS) Measurement of Single-Fiber GNFs/CF Hybrids. To determine the interfacial adhesion between the fibers and the matrix, interfacial shear strength (IFSS) was measured by single-fiber fragmentation test (SFFT), following the methodology described in section 2.3. The IFSS was analyzed by the Kelly and Tyson model ${ }^{53}$ given in eqs 4-7. Photoelastic birefringence patterns, induced by stress concentrations at the fiber/matrix interface, in the vicinity of fiber fragments, were observed by polarized optical microscopy, and their lengths were measured. It can be seen in Figure 5 that the introduction of a GNFs interface significantly

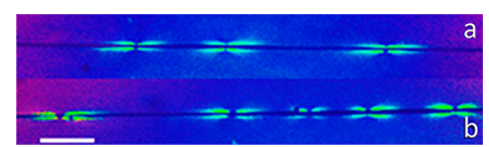

Figure 5. Representative photoelastic birefringence patterns of (a) bare (bCF) and (b) GCF-2 ( $800 \mathrm{~W}$ at $600{ }^{\circ} \mathrm{C}$ ) hybrid fiber, observed by polarized optical microscopy during the single-fiber fragmentation test $(\mathrm{SFFT})$. Scale bar $=50 \mu \mathrm{m}$.

increases the fracture density in the GCF- $2\left(800 \mathrm{~W}\right.$ at $\left.600{ }^{\circ} \mathrm{C}\right)$ specimen, which indicates improved fiber/matrix interfacial shear strength. The calculated IFSS was found to increase from $15.10 \pm 3.61 \mathrm{MPa}$ for the bare fiber $(\mathrm{bCF})$ to $30.43 \pm 4.30$ $\mathrm{MPa}$ with the GNFs interface (GCF-2 $\left(800 \mathrm{~W}\right.$ at $\left.600{ }^{\circ} \mathrm{C}\right)$ hybrid), indicating an enhancement by $101.5 \%$ (Figure 6 and Table S3). This increase is in good agreement with recent results of rf-PECVD grown $\mathrm{GNFs}^{49-51}$ as well as with other nanomaterials like CNTs ${ }^{8,75}$ or $\mathrm{ZnO}$ nanowires ${ }^{68,76}$ grown on CFs. Improvement of IFSS could be attributed to the following reasons: (i) The dense labyrinth-like network of the GNFs creates a higher surface area on CFs, which leads to improved mechanical interlocking. (ii) The large number of edge defects present in GNFs promotes strong bonding with the epoxy. (iii) The gradient distribution of graphene layers along the nanoflakes' height (progressively reducing from the bottom to the top of nanoflake) produces essentially a gradient

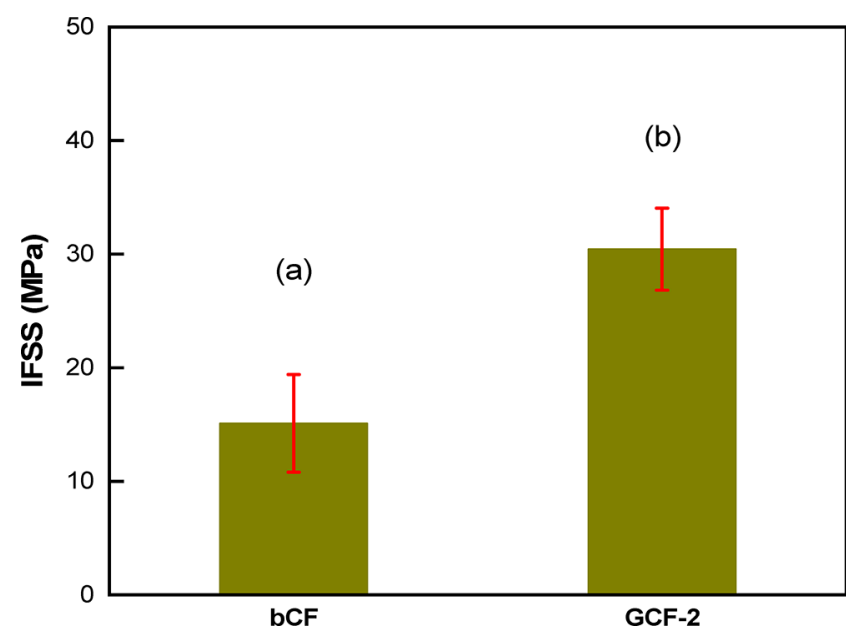

Figure 6. Interfacial shear strength (IFSS) results for (a) bare (bCF) and (b) GCF-2 ( $800 \mathrm{~W}$ at $600{ }^{\circ} \mathrm{C}$ ) hybrid fiber conducted via singlefiber fragmentation test. Error bars represent standard deviation from at least 20 independent measurements.

between the fiber and matrix, which can effectively transfer load and thus reduce stress concentration at the interface.

SEM fractography analysis (Figure 7) was carried out to investigate the failure mechanisms at the interfaces and simultaneously examine whether the existence of the GNFs coating could possibly lead to enhanced interfacial adhesion. An epoxy resin/CF bundle, in dog-bone shape, was broken via a universal tensile strength tester to simulate a typical pull-out test.

Bare fibers displayed significant fiber pull-out from the polymer matrix (Figure 7a), presenting a large quantity of holes, indicative of poor adhesion between the CFs and the epoxy resin surrounding them, when compared to coated ones (Figure $7 d$ ). Figures $7 \mathrm{~b}, \mathrm{c}$ revealed significant fiber debonding or adhesive failure of the interface between bare CFs and the polymer matrix, while Figures $7 \mathrm{e}$,f disclosed that the presence of GNFs established bridging effects between the coated CFs and the polymer matrix, transferring in this way stresses in the region between the CF and the epoxy resin. The growth of GNFs on the surface of carbon fibers led to the formation of two interfaces: one between the CF and GNFs and a second one between the GNF and the epoxy matrix. The increased interface strength resulting from the GNFs implies that both interfaces were stronger than that between the bCF and epoxy of the bCF composite. The increased strength of the GNFs/ epoxy interface is attributed to increased bond area due to the high surface area of the GNFs, whereas the increased adhesion between the carbon fiber and GNFs is associated with the energetic nature of the plasma.

3.5. Electrical Conductivity $(\sigma)$ of GNFs/CF Hybrid Single Fibers and Yarns. The electrical conductivity of CF yarns before and after the introduction of GNFs is shown in Figure $8 \mathrm{a}$. The electrical conductivity of the yarns was calculated by multiplying the measured conductance with the distance between two electrode contacts and dividing the resultant product with the cross-sectional area of the fiber (cylindrical shape assumption, eq 8). The calculated value was then multiplied by the number of individual fibers consisting the yarn (12000) to evaluate the yarn's conductance. The asreceived carbon fiber yarn had a conductivity of $\sim 160 \mathrm{~S} \mathrm{~cm}^{-1}$, which increased for almost all hybrid yarns. The highest 

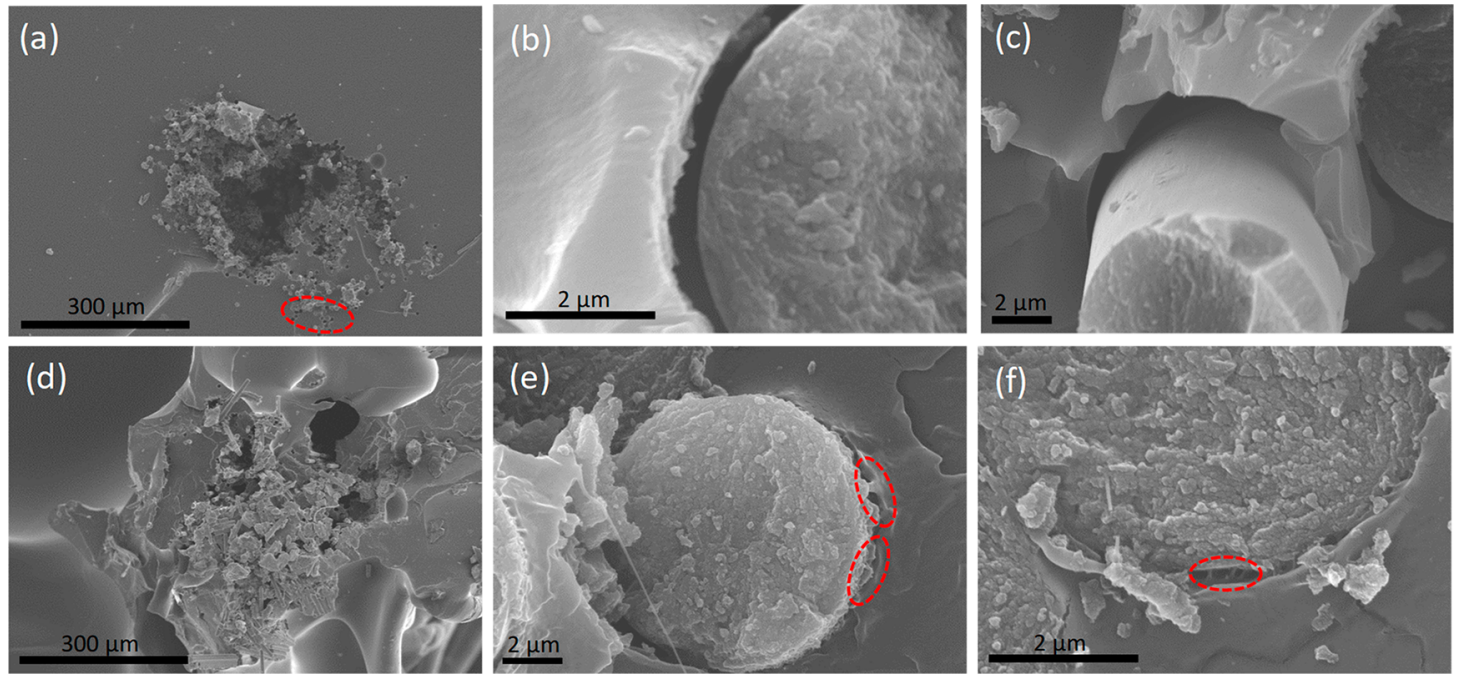

Figure 7. SEM photographs of the fracture surfaces after the fragmentation test: $(a-c)$ represent specimens of bare (bCF) fibers in polymer matrix and $(\mathrm{d}-\mathrm{f})$ represent specimens of GNF-coated CFs surface $\left(\mathrm{GCF}-2\left(800 \mathrm{~W}\right.\right.$ at $\left.600{ }^{\circ} \mathrm{C}\right)$ hybrid) in a polymer matrix.
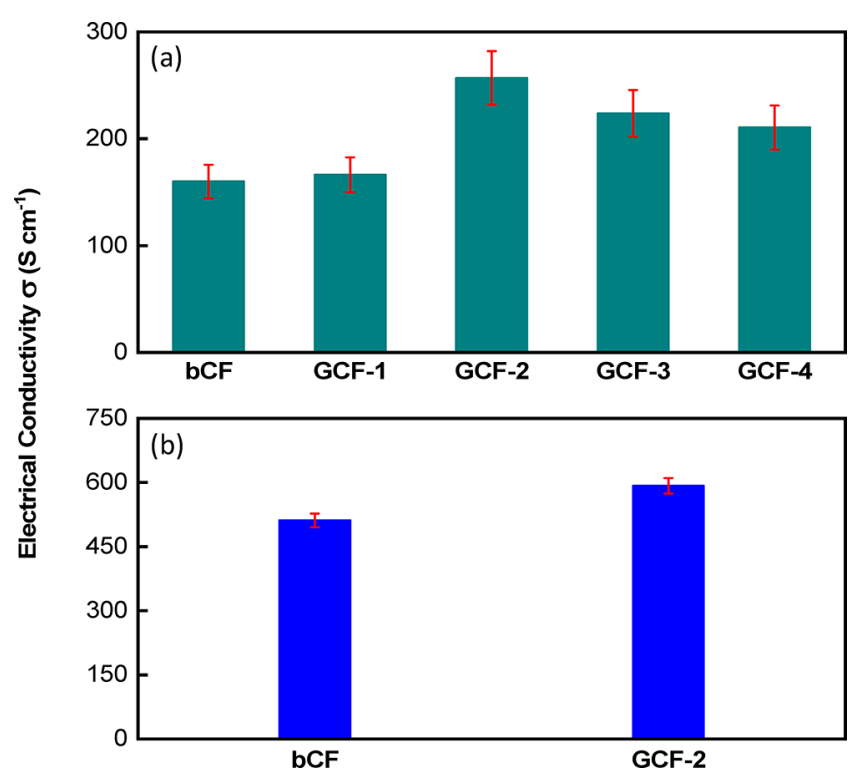

Figure 8. Electrical conductivity $(\sigma)$ measurements. (a) Electrical conductivity of bare (bCF) and GNFs/CF hybrid yarns: GCF-1 (500 $\mathrm{W}$ at $\left.600{ }^{\circ} \mathrm{C}\right), \mathrm{GCF}-2\left(800 \mathrm{~W}\right.$ at $\left.600{ }^{\circ} \mathrm{C}\right), \mathrm{GCF}-3\left(950 \mathrm{~W}\right.$ at $\left.600{ }^{\circ} \mathrm{C}\right)$, and GCF-4 (800 W at $\left.300{ }^{\circ} \mathrm{C}\right)$. (b) Electrical conductivity measurements of bare (bCF) and GCF-2 hybrid single fibers. Error bars represent standard deviation from at least 20 independent measurements.

electrical conductivity value was observed for GCF-2 (800 W at $\left.600{ }^{\circ} \mathrm{C}\right), 257 \mathrm{~S} \mathrm{~cm}^{-1}$, displaying an increase of $\sim 60.5 \%$. Hybrid yarns fabricated at high microwave power (GCF-2, GCF-3, and GCF-4) exhibited increased electrical conductivity when compared to GCF-1 ( $500 \mathrm{~W}$ at $600{ }^{\circ} \mathrm{C}$ ) synthesized at the lowest microwave power, which behaved like the bare yarn. This enhancement in electrical conductivity can be attributed to the better crystallinity of the GNFs associated with intense plasmas, achieved at higher microwave powers, as evident from the lower $I_{\mathrm{D}} / I_{\mathrm{G}}$ ratio (Figure S13). Single fiber electrical conductivity measurements were also performed on the best sample (GCF-2). The conductivity of the hybrid fiber (Figure $8 \mathrm{~b}$ ) increased from 511 to $592 \mathrm{~S} \mathrm{~cm}^{-1}$, indicating an increase of about $16 \%$. It is noteworthy that there is no relative work on the literature that reports on the electrical conductivity of GNFs/CF hybrids.

3.6. Electrochemical Capacitance Measurements of GNFs/CF Hybrid Yarns. Bare and GNFs/CF yarns were characterized by electrochemical methods that are aligned with electrochemical storage application. It should be noted here that these initial electrochemical studies reported here serve only as preliminary work toward implementation of GNFs/CF in structural power applications. Capacitance measurements were made in fresh $1.0 \mathrm{M} \mathrm{H}_{2} \mathrm{SO}_{4}(\mathrm{pH} 0)$ and $1.0 \mathrm{M} \mathrm{NaClO}_{4}$ ( $\mathrm{pH} 7.4$ ) electrolytes by employing cyclic voltammetry (CV), recorded in a three-electrode configuration. Notably, CV studies exhibited a slightly wider operating voltage window of $1.15 \mathrm{~V}(-0.15$ to $+1.0 \mathrm{~V})$ in $\mathrm{NaClO}_{4}$ electrolyte compared to $1.0 \mathrm{~V}(0.0$ to $+1.0 \mathrm{~V})$ in $1.0 \mathrm{M} \mathrm{H}_{2} \mathrm{SO}_{4}$. In both electrolytes, the specific capacitance $\left(C_{\mathrm{sp}}\right.$, Figure $\left.9 \mathrm{a}\right)$ and energy efficiency $\left(\eta_{\mathrm{E}}\right.$, Figure $9 \mathrm{~b}$ ), derived by using eqs 9 and 10, respectively, exhibited a similar magnitude and trend for the various GNF coatings on $\mathrm{CF}$ yarns, demonstrating nonsensitivity to the electrolyte $\mathrm{pH}$. The GNFs/CF hybrid electrodes (Figures $\mathrm{S} 14 \mathrm{~b}-\mathrm{e}$ and $\mathrm{S} 15 \mathrm{~b}-\mathrm{e}$ ) exhibited distinctive surface redox activity (Supporting Information section S9 and Figure S16) originating from the formation of quinonoidal $(\mathrm{C}=\mathrm{O})$ groups on graphitic edges surfaces of $\mathrm{GNFs}^{77-80}$ and contributed to positive efficiency $\eta_{\mathrm{E}}$ values at increasing scanning rates (Figures $\mathrm{S} 14 \mathrm{~g}$ and $\mathrm{S} 15 \mathrm{~g}$ ). In contrast, bare CF electrodes presented inclined CV envelops (Figures S14a and S15a), exhibiting negative efficiency $\left(\eta_{\mathrm{E}}\right)$ values (Figures $\mathrm{S} 14 \mathrm{~g}$ and $\mathrm{S} 15 \mathrm{~g}$ ), most probably due to the insulating nature of the sizing, undoubtedly indicating inaptness for supercapacitor application.

The best performance was observed for the GCF-2 (800 W at $\left.600{ }^{\circ} \mathrm{C}\right)$ hybrid yarn, exhibiting $>2$ times higher $C_{\mathrm{sp}}(0.65$ $\left.\mathrm{mF} / \mathrm{cm}^{2}\right)$ and almost ideal $\eta_{\mathrm{E}}$ value $(\approx 100 \%)$, in both electrolytes, in comparison to $\mathrm{bCF}\left(C_{\mathrm{sp}} \approx 0.27 \mathrm{mF} / \mathrm{cm}^{2}\right.$ and negative $\eta_{\mathrm{E}}$ ), demonstrating the potential of GNFs/CF hybrid yarn electrodes for electrochemical energy storage. Such enhanced capacitance of GNFs/CF hybrids over the bCFs yarn electrodes is attributed to the improved electrical conductivity and hierarchical porous structure of GNFs, endowing higher charge transfer and accessible electroactive surface area (ESA) for ion adsorption, respectively. 

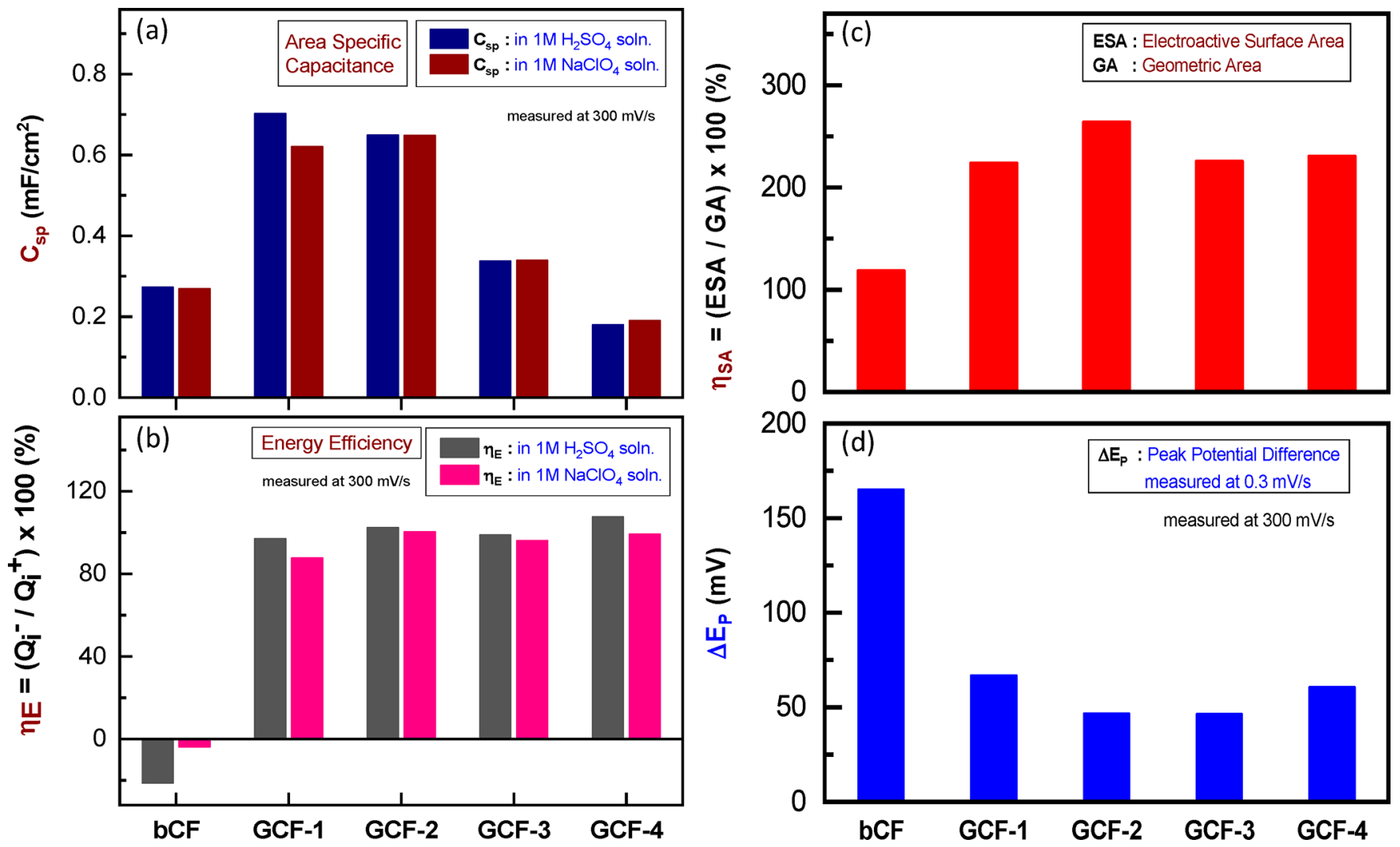

Figure 9. (a) Specific capacitance $\left(C_{\mathrm{sp}}\right)$ of bare (bCF) and GNFs/CF hybrid yarn electrodes: GCF-1 (500 W at $\left.600{ }^{\circ} \mathrm{C}\right)$, GCF-2 (800 W at 600 $\left.{ }^{\circ} \mathrm{C}\right)$, GCF-3 $\left(950 \mathrm{~W}\right.$ at $\left.600{ }^{\circ} \mathrm{C}\right)$, and GCF-4 $\left(800 \mathrm{~W}\right.$ at $\left.300{ }^{\circ} \mathrm{C}\right)$, derived from the CV curves recorded at the potential scan rate $(\nu)$ of $300 \mathrm{mV} / \mathrm{s}$, in acidic $\left(1.0 \mathrm{M} \mathrm{H}_{2} \mathrm{SO}_{4}\right)$ and neutral $\left(1.0 \mathrm{M} \mathrm{NaClO}_{4}\right)$ electrolytes. (b) Corresponding energy efficiency $\left(\eta_{\mathrm{E}}\right)$ values. The $300 \mathrm{mV} / \mathrm{s}$ is chosen to represent the data here because the estimated $C_{\mathrm{sp}}$ and $\eta_{\mathrm{E}}$ values reach a saturation level around this high $\nu$ (Figures S14f,g and S15f,g). (c) Electrocatalytic efficiencies $\left(\eta_{\mathrm{SA}}\right)$ of bCF and GNFs/CF hybrid yarn electrodes. (d) Corresponding redox peak potential difference $\left(\Delta E_{\mathrm{p}}\right.$, recorded at $\nu$ of $300 \mathrm{mV} / \mathrm{s})$, derived from the redox activity of $\mathrm{Fe}(\mathrm{CN})_{6}^{3-/ 4-}$, in $5 \mathrm{mM} \mathrm{K}_{4} \mathrm{Fe}(\mathrm{CN})_{6}$ in $0.1 \mathrm{M} \mathrm{KCl}$ solution.

3.6.1. Electrochemical Redox Activity Study on GNFs/CF Hybrid Yarns. To evaluate the improvement in ESA, the electrocatalytic properties of bCF and GNFs/CFs yarn electrodes were probed for $\mathrm{Fe}(\mathrm{CN})_{6}{ }^{3-/ 4-}$ redox activity. As expected, all GNFs/CF hybrid yarn electrodes exhibited obvious redox peak currents with narrow peak potential difference, $\Delta E_{\mathrm{p}}$, indicating a higher ESA and enhanced catalytic performance (Figure S17), relative to the sluggish redox performance of bCF (Figure S17a).

Both bCF and GNFs/CF hybrid electrodes displayed linear relationship of the redox peak currents $\left(I_{\mathrm{p}}\right)$ with the square root of potential scan rates $\left(\nu^{1 / 2}\right)$, as displayed in Figure S17f, suggesting a diffusion-controlled mass transport. To compare the electrocatalytic efficiency of GNFs/CF hybrid yarn electrodes, the measured efficiency parameter, $\eta_{\mathrm{SA}}=(\mathrm{ESA} /$ GA) $\times 100 \%$ (derived from eqs 11 and 12 ), was introduced, where ESA and GA are electroactive and geometric surface area of electrode $\left(\mathrm{cm}^{2}\right)$, respectively (Table S4). Both high $\eta_{\mathrm{SA}}$ (Figures 9c) and low $\Delta E_{\mathrm{p}}$ (Figures 9d) values reveal electrocatalytic performance for GNFs/CF hybrid yarn electrodes superior to bCFs, supporting the same trend observed for the capacitance studies (Figure 9a,b).

Improvement in the interfacial conductivity between the deposited graphene (GNFs) and the CFs template could easily be evidenced from the electrochemical impedance study, illustrated in Figure S18. The mw-PECVD-synthesized GNFs improved the interfacial electron-transfer resistance significantly, as observed in the Nyquist plots (Figure S18a), reducing the overall impedance magnitude (Bode plot, Figure $\mathrm{S} 18 \mathrm{~b})$. The improved interfacial conductivity is attributed to the low contact resistance between the directly grown GNFs and the carbon fiber yarn.

\section{CONCLUSIONS}

In summary, graphene nanoflakes (GNFs) grown by a microwave plasma enhanced CVD (mw-PECVD) process in a few minutes were investigated for the first time as a novel and simple route to reinforce the interface of CF composites and simultaneously impart multifunctional attributes. Hybrid carbon fiber composites with a GNF interphase were developed, and the role of the GNFs morphology on inplane mechanical properties was assessed through single-fiber tests, while their electrical and capacitive performance was assessed via electrical and electrochemical tests on single fibers or yarns. Our results showed that under optimized conditions the growth of GNFs not only avoids the deterioration of the in-plane mechanical properties usually met in CF reinforcements by other nanomaterials but also leads to a remarkable improvement of $\sim 28 \%$ in tensile strength compared to control bare fibers. Such enormous enhancement in tensile strength is much higher than any previously reported improvement. This tremendous increase in tensile strength is associated with (i) a reduced thermal loading on the CF due to quick GNF growth of only few minutes, (ii) the elimination of harmful chemical procedures prior to growth as no catalyst is required, and (iii) the highly crystalline quality of GNFs that helps to restrict 
crack propagation. Single carbon fiber fragmentation tests (SFFT) revealed that the GNFs give rise to a $101.5 \%$ enhancement in the interfacial shear strength over the control bare carbon fiber, indicating a strong coupling between the GNFs and the epoxy matrix. The increased surface, the abundance of edge defects, and the gradient interface of GNF network were considered as important factors that led to the improved interlocking between the GNF and epoxy matrix. Moreover, the direct contact between the GNFs and CF contributed to reduced contact resistance, leading to significant improvements in electrical conductivity $(60.5 \%)$ and electrochemical capacitance (157\%) over as-purchased control fibers. Consequently, all these improvements in tensile and interfacial shear strength as well as electrical conductivity and electrochemical capacitance demonstrate the significant potential GNFs as a reinforcement interface for the manufacturing of future multifunctional carbon fiber reinforced polymer composites.

\section{ASSOCIATED CONTENT}

\section{SI Supporting Information}

The Supporting Information is available free of charge at https://pubs.acs.org/doi/10.1021/acsanm.9b02536.

Direct growth of GNFs on carbon fibers, materials, estimation of fiber diameters using Renishaw Invia Qontor system, Raman analysis of the GNFs/CF hybrids; SEM observations of GNFs/CF hybrids; electrical conductivity measurements; mechanical characterization of the hybrid fibers via single-fiber tensile strength measurements; preparation and testing of specimens; interfacial shear strength measurement (IFSS) of GNFs/CF hybrids; electrochemical characterization (PDF)

\section{AUTHOR INFORMATION}

\section{Corresponding Author}

Pagona Papakonstantinou - School of Engineering, Engineering Research Institute, Ulster University, Newtownabbey BT37 OQB, United Kingdom; (1) orcid.org/0000-0003-00193247; Email: p.papakonstantinou@ulster.ac.uk

\section{Authors}

Anastasios Karakassides - School of Engineering, Engineering Research Institute, Ulster University, Newtownabbey BT37 $O Q B$, United Kingdom

Abhijit Ganguly - School of Engineering, Engineering Research Institute, Ulster University, Newtownabbey BT37 OQB, United Kingdom; (1) orcid.org/0000-0002-8852-2721

Kyriaki Tsirka - Composite and Smart Materials Laboratory, Department of Materials Science and Engineering, University of Ioannina, Ioannina, Greece

Alkiviadis S. Paipetis - Composite and Smart Materials Laboratory, Department of Materials Science and Engineering, University of Ioannina, Ioannina, Greece

Complete contact information is available at:

https://pubs.acs.org/10.1021/acsanm.9b02536

\section{Notes}

The authors declare no competing financial interest.

\section{ACKNOWLEDGMENTS}

The authors acknowledge support from the Air Force Office of Scientific Research (AFOSR) under Grant FA9550-17-1-0042 and the Department of Education in Northern Ireland and Ulster University for providing a $\mathrm{PhD}$ studentship to A.K.

\section{REFERENCES}

(1) Yao, H.; Sui, X.; Zhao, Z.; Xu, Z.; Chen, L.; Deng, H.; Liu, Y.; Qian, X. Optimization of interfacial microstructure and mechanical properties of carbon fiber/epoxy composites via carbon nanotube sizing. Appl. Surf. Sci. 2015, 347, 583-590.

(2) Shazed, M. A.; Suraya, A. R.; Rahmanian, S.; Mohd Salleh, M. A. Effect of fibre coating and geometry on the tensile properties of hybrid carbon nanotube coated carbon fibre reinforced composite. Mater. Eng. 2014, 54, 660-669.

(3) Li, F.; Liu, Y.; Qu, C. B.; Xiao, H. M.; Hua, Y.; Sui, G. X.; Fu, S. $\mathrm{Y}$. Enhanced mechanical properties of short carbon fiber reinforced polyethersulfone composites by graphene oxide coating. Polymer 2015, 59, 155-165.

(4) Pathak, A. K.; Borah, M.; Gupta, A.; Yokozeki, T.; Dhakate, S. R. Improved mechanical properties of carbon fiber/graphene oxideepoxy hybrid composites. Compos. Sci. Technol. 2016, 135, 28-38.

(5) Iqbal, H. M. S.; Bhowmik, S.; Benedictus, R. Surface modification of high performance polymers by atmospheric pressure plasma and failure mechanism of adhesive bonded joints. Int. J. Adhes. Adhes. 2010, 30, 418-424.

(6) Lee, E.; Lee, C.; Chun, Y.-S.; Han, C.; Lim, D.-S. Effect of hydrogen plasma-mediated surface modification of carbon fibers on the mechanical properties of carbon-fiber-reinforced polyetherimide composites. Composites, Part B 2017, 116, 451-458.

(7) Xie, J.; Xin, D.; Cao, H.; Wang, C.; Zhao, Y.; Yao, L.; Ji, F.; Qiu, Y. Improving carbon fiber adhesion to polyimide with atmospheric pressure plasma treatment. Surf. Coat. Technol. 2011, 206, 191-201.

(8) Peng, Q.; He, X.; Li, Y.; Wang, C.; Wang, R.; Hu, P.; Yan, Y.; Sritharan, T. Chemically and uniformly grafting carbon nanotubes onto carbon fibers by poly(amidoamine) for enhancing interfacial strength in carbon fiber composites. J. Mater. Chem. 2012, 22, 5928.

(9) Zhang, X.; Xu, H.; Fan, X. Grafting of amine-capped cross-linked polyphosphazenes onto carbon fiber surfaces: A novel coupling agent for fiber reinforced composites. RSC Adv. 2014, 4, 12198-12205.

(10) Yang, K.; Gu, M.; Guo, Y.; Pan, X.; Mu, G. Effects of carbon nanotube functionalization on the mechanical and thermal properties of epoxy composites. Carbon 2009, 47, 1723-1737.

(11) Qian, H.; Bismarck, A.; Greenhalgh, E. S.; Shaffer, M. S. P. Carbon nanotube grafted carbon fibres: A study of wetting and fibre fragmentation. Composites, Part A 2010, 41, 1107-1114.

(12) Islam, M. S.; Deng, Y.; Tong, L.; Faisal, S. N.; Roy, A. K.; Minett, A. I.; Gomes, V. G. Grafting carbon nanotubes directly onto carbon fibers for superior mechanical stability: Towards next generation aerospace composites and energy storage applications. Carbon 2016, 96, 701-710.

(13) Guo, J.; Lu, C.; An, F. Effect of electrophoretically deposited carbon nanotubes on the interface of carbon fiber reinforced epoxy composite. J. Mater. Sci. 2012, 47, 2831-2836.

(14) Zhitomirsky, I. Electrophoretic and electrolytic deposition of ceramic coatings on carbon fibers. J. Eur. Ceram. Soc. 1998, 18, 849856.

(15) Bekyarova, E.; Thostenson, E. T.; Yu, A.; Kim, H.; Gao, J.; Tang, J.; Hahn, H. T.; Chou, T. W.; Itkis, M. E.; Haddon, R. C. Multiscale carbon nanotube-carbon fiber reinforcement for advanced epoxy composites. Langmuir 2007, 23, 3970-3974.

(16) Moniruzzaman, M.; Winey, K. I. Polymer nanocomposites containing carbon nanotubes. Macromolecules 2006, 39, 5194-5205.

(17) Ma, P. C.; Siddiqui, N. A.; Marom, G.; Kim, J. K. Dispersion and functionalization of carbon nanotubes for polymer-based nanocomposites: A review. Composites, Part A 2010, 41, 1345-1367. 
(18) Xie, X. L.; Mai, Y. W.; Zhou, X. P. Dispersion and alignment of carbon nanotubes in polymer matrix: A review. Mater. Sci. Eng., $R$ 2005, 49, 89-112.

(19) Tkalya, E. E.; Ghislandi, M.; de With, G.; Koning, C. E. The use of surfactants for dispersing carbon nanotubes and graphene to make conductive nanocomposites. Curr. Opin. Colloid Interface Sci. 2012, $17,225-232$.

(20) Stankovich, S.; Dikin, D. A.; Dommett, G. H. B.; Kohlhaas, K. M.; Zimney, E. J.; Stach, E. A.; Piner, R. D.; Nguyen, S. B. T.; Ruoff, R. S. Graphene-based composite materials. Nature 2006, 442, 282286.

(21) Kim, K. J.; Yu, W. R.; Youk, J. H.; Lee, J. Degradation and healing mechanisms of carbon fibers during the catalytic growth of carbon nanotubes on their surfaces. ACS Appl. Mater. Interfaces 2012, 4, 2250-2258.

(22) Kim, K. J.; Kim, J.; Yu, W. R.; Youk, J. H.; Lee, J. Improved tensile strength of carbon fibers undergoing catalytic growth of carbon nanotubes on their surface. Carbon 2013, 54, 258-267.

(23) Qian, H.; Bismarck, A.; Greenhalgh, E. S.; Kalinka, G.; Shaffer, M. S. P. Hierarchical composites reinforced with carbon nanotube grafted fibers: The potential assessed at the single fiber level. Chem. Mater. 2008, 20, 1862-1869.

(24) Sager, R. J.; Klein, P. J.; Lagoudas, D. C.; Zhang, Q.; Liu, J.; Dai, L.; Baur, J. W. Effect of carbon nanotubes on the interfacial shear strength of T650 carbon fiber in an epoxy matrix. Compos. Sci. Technol. 2009, 69, 898-904.

(25) Lee, G.; Youk, J. H.; Lee, J.; Sul, I. H.; Yu, W. R. Lowtemperature grafting of carbon nanotubes on carbon fibers using a bimetallic floating catalyst. Diamond Relat. Mater. 2016, 68, 118-126.

(26) Steiner, S. A.; Li, R.; Wardle, B. L. Circumventing the mechanochemical origins of strength loss in the synthesis of hierarchical carbon fibers. ACS Appl. Mater. Interfaces 2013, 5, 4892-4903.

(27) Li, R.; Lachman, N.; Florin, P.; Wagner, H. D.; Wardle, B. L. Hierarchical carbon nanotube carbon fiber unidirectional composites with preserved tensile and interfacial properties. Compos. Sci. Technol. 2015, 117, 139-145.

(28) Wu, Y.; Qiao, P.; Chong, T.; Shen, Z. Carbon nanowalls grown by microwave plasma enhanced chemical vapor deposition. Adv. Mater. 2002, 14, 64-67.

(29) Hiramatsu, M.; Kondo, H.; Hori, M. Graphene Nanowalls. In New Progress on Graphene Research; InTech: 2013; pp 235-260.

(30) Saviers, K. R.; Alrefae, M. A.; Fisher, T. S. Roll-to-Roll Production of Graphitic Petals on Carbon Fiber Tow. Adv. Eng. Mater. 2018, 20, 1800004.

(31) Kumar, A.; Ayyagari, N.; Fisher, T. S. Effects of Graphene Nanopetal Outgrowths on Internal Thermal Interface Resistance in Composites. ACS Appl. Mater. Interfaces 2016, 8, 6678-6684.

(32) Shang, N. G.; Papakonstantinou, P.; McMullan, M.; Chu, M.; Stamboulis, A.; Potenza, A.; Dhesi, S. S.; Marchetto, H. Catalyst-free efficient growth, orientation and biosensing properties of multilayer graphene nanoflake films with sharp edge planes. Adv. Funct. Mater. 2008, 18, 3506-3514.

(33) Shang, N.; Kumar, A.; Sun, N.; Sharma, S.; Papakonstantinou, P.; Li, M.; Blackley, R. A.; Zhou, W.; Karlsson, L. S.; Silva, S. R. P. Vertical graphene nanoflakes for the immobilization, electrocatalytic oxidation and quantitative detection of DNA. Electrochem. Commun. 2012, 25, 140-143.

(34) Shang, N.; Papakonstantinou, P.; Wang, P.; Silva, S. R. P. Platinum integrated graphene for methanol fuel cells. J. Phys. Chem. C 2010, 114, 15837-15841.

(35) Wegst, U. G. K.; Bai, H.; Saiz, E.; Tomsia, A. P.; Ritchie, R. O. Bioinspired structural materials. Nat. Mater. 2015, 14, 23-36.

(36) Hojati-Talemi, P.; Simon, G. P. Field emission study of graphene nanowalls prepared by microwave-plasma method. Carbon 2011, 49, 2875-2877.

(37) Krivchenko, V. A.; Evlashin, S. A.; Mironovich, K. V.; Verbitskiy, N. I.; Nefedov, A.; Woll, C.; Kozmenkova, A. Y.; Suetin, N. V.; Svyakhovskiy, S. E.; Vyalikh, D. V.; Rakhimov, A. T.; Egorov, A.
V.; Yashina, L. V. Carbon nanowalls: the next step for physical manifestation of the black body coating. Sci. Rep. 2013, 3, 3328.

(38) Chen, Q.; Sun, T.; Song, X.; Ran, Q.; Yu, C.; Yang, J.; Feng, H.; Yu, L.; Wei, D. Flexible electrochemical biosensors based on graphene nanowalls for the real-time measurement of lactate. Nanotechnology 2017, 28, 315501.

(39) Mao, S.; Yu, K.; Chang, J.; Steeber, D. A.; Ocola, L. E.; Chen, J. Direct growth of vertically-oriented graphene for field-effect transistor biosensor. Sci. Rep. 2013, 3, 1696.

(40) Akhavan, O.; Ghaderi, E.; Rahighi, R. Toward single-DNA electrochemical biosensing by graphene nanowalls. ACS Nano 2012, 6, 2904-2916.

(41) Hiramatsu, M.; Mitsuguchi, S.; Horibe, T.; Kondo, H.; Hori, M.; Kano, H. Fabrication of carbon nanowalls on carbon fiber paper for fuel cell application. Jpn. J. Appl. Phys. 2013, 52, 01 AK03.

(42) Lehmann, K.; Yurchenko, O.; Urban, G. Carbon Nanowalls for oxygen reduction reaction in Bio Fuel Cells. J. Phys.: Conf. Ser. 2014, $557,012008$.

(43) Yen, H. F.; Horng, Y. Y.; Hu, M. S.; Yang, W. H.; Wen, J. R.; Ganguly, A.; Tai, Y.; Chen, K. H.; Chen, L. C. Vertically aligned epitaxial graphene nanowalls with dominated nitrogen doping for superior supercapacitors. Carbon 2015, 82, 124-134.

(44) Li, J.; Zhu, M.; An, Z.; Wang, Z.; Toda, M.; Ono, T. Constructing in-chip micro-supercapacitors of $3 \mathrm{D}$ graphene nanowall/ruthenium oxides electrode through silicon-based microfabrication technique. J. Power Sources 2018, 401, 204-212.

(45) Li, J.; Zhu, M.; Wang, Z.; Ono, T. Engineering microsupercapacitors of graphene nanowalls/Ni heterostructure based on microfabrication technology. Appl. Phys. Lett. 2016, 109, 153901.

(46) Hsu, H. C.; Wang, C. H.; Nataraj, S. K.; Huang, H. C.; Du, H. Y.; Chang, S. T.; Chen, L. C.; Chen, K. H. Stand-up structure of graphene-like carbon nanowalls on CNT directly grown on polyacrylonitrile-based carbon fiber paper as supercapacitor. Diamond Relat. Mater. 2012, 25, 176-179.

(47) Lin, G.; Zhou, Y.; Wang, Y.; Yan, X.; Wu, B.; Huang, F.; Fu, J.; Cheng, Q.; Yun, D. Direct growth of graphene nanowalls on quartz substrates as transparent conductive electrodes for perovskite solar cells. Funct. Mater. Lett. 2018, 11, 1850009.

(48) Jiao, T.; Liu, J.; Wei, D.; Feng, Y.; Song, X.; Shi, H.; Jia, S.; Sun, W.; Du, C. Composite transparent electrode of graphene nanowalls and silver nanowires on micropyramidal Si for high-efficiency schottky junction solar cells. ACS Appl. Mater. Interfaces 2015, 7, 2017920183.

(49) Chi, Y.; Chu, J.; Chen, M.; Li, C.; Mao, W.; Piao, M.; Zhang, H.; Liu, B. S.; Shi, H. Directly deposited graphene nanowalls on carbon fiber for improving the interface strength in composites. Appl. Phys. Lett. 2016, 108, 211601.

(50) Wang, X.; Li, C.; Chi, Y.; Piao, M.; Chu, J.; Zhang, H.; Li, Z.; Wei, W. Effect of graphene nanowall size on the interfacial strength of carbon fiber reinforced composites. Nanomaterials 2018, 8, 414.

(51) Sha, Z.; Han, Z.; Wu, S.; Zhang, F.; Islam, M. S.; Brown, S. A.; Wang, C. H. Low-temperature plasma assisted growth of vertical graphene for enhancing carbon fibre/epoxy interfacial strength. Compos. Sci. Technol. 2019, 184, 107867.

(52) ASTM, C. 1557-03. Standard test method for tensile strength and Young's modulus of fibers, ASTM International, 2003.

(53) Kelly, A.; Tyson, W. R. Tensile properties of fibre-reinforced metals: Copper/tungsten and copper/molybdenum. J. Mech. Phys. Solids 1965, 13, 329-350.

(54) Wolfenden, A.; van der Zwaag, S. The Concept of Filament Strength and the Weibull Modulus. J. Test. Eval. 1989, 17, 292.

(55) Tomiyasu, H.; Shikata, H.; Takao, K.; Asanuma, N.; Taruta, S.; Park, Y.-Y. An aqueous electrolyte of the widest potential window and its superior capability for capacitors. Sci. Rep. 2017, 7, 45048.

(56) Cançado, L. G.; Jorio, A.; Ferreira, E. H. M.; Stavale, F.; Achete, C. A.; Capaz, R. B.; Moutinho, M. V. O.; Lombardo, A.; Kulmala, T. S.; Ferrari, A. C. Quantifying Defects in Graphene via Raman Spectroscopy at Different Excitation Energies. Nano Lett. 2011, 11, $3190-3196$ 
(57) Hao, Q.; Morton, S. M.; Wang, B.; Zhao, Y.; Jensen, L.; Jun Huang, T. Tuning surface-enhanced Raman scattering from graphene substrates using the electric field effect and chemical doping. Appl. Phys. Lett. 2013, 102, 011102.

(58) Ferrari, A. C.; Meyer, J. C.; Scardaci, V.; Casiraghi, C.; Lazzeri, M.; Mauri, F.; Piscanec, S.; Jiang, D.; Novoselov, K. S.; Roth, S.; Geim, A. K. Raman spectrum of graphene and graphene layers. Phys. Rev. Lett. 2006, 97, 187401.

(59) Kastner, J.; Pichler, T.; Kuzmany, H.; Curran, S.; Blau, W.; Weldon, D. N.; Delamesiere, M.; Draper, S.; Zandbergen, H. Resonance Raman and infrared spectroscopy of carbon nanotubes. Chem. Phys. Lett. 1994, 221, 53-58.

(60) Childres, I.; Jauregui, L. A.; Tian, J.; Chen, Y. P. Effect of oxygen plasma etching on graphene studied using Raman spectroscopy and electronic transport measurements. New J. Phys. 2011, 13, 025008 .

(61) Chan, S. H.; Chen, J. W.; Chen, H. P.; Wei, H. S.; Li, M. C.; Chen, S. H.; Lee, C. C.; Kuo, C. C. The deviation of growth model for transparent conductive graphene. Nanoscale Res. Lett. 2014, 9, 581.

(62) Shiji, K.; Hiramatsu, M.; Enomoto, A.; Nakamura, M.; Amano, $\mathrm{H}$.; Hori, M. Vertical growth of carbon nanowalls using rf plasmaenhanced chemical vapor deposition. Diamond Relat. Mater. 2005, 14, 831-834.

(63) Nong, J.; Wei, W.; Song, X.; Tang, L.; Yang, J.; Sun, T.; Yu, L.; Luo, W.; Li, C.; Wei, D. Direct growth of graphene nanowalls on silica for high-performance photo-electrochemical anode. Surf. Coat. Technol. 2017, 320, 579-583.

(64) Song, X.; Liu, J.; Yu, L.; Yang, J.; Fang, L.; Shi, H.; Du, C.; Wei, D. Direct versatile PECVD growth of graphene nanowalls on multiple substrates. Mater. Lett. 2014, 137, 25-28.

(65) Makris, T. D.; Giorgi, L.; Giorgi, R.; Lisi, N.; Salernitano, E. CNT growth on alumina supported nickel catalyst by thermal CVD. Diamond Relat. Mater. 2005, 14, 815-819.

(66) Zhu, S.; Su, C. H.; Lehoczky, S. L.; Muntele, I.; Ila, D. Carbon nanotube growth on carbon fibers. Diamond Relat. Mater. 2003, 12, $1825-1828$.

(67) Fan, W.; Wang, Y.; Wang, C.; Chen, J.; Wang, Q.; Yuan, Y.; Niu, F. High efficient preparation of carbon nanotube-grafted carbon fibers with the improved tensile strength. Appl. Surf. Sci. 2016, 364, $539-551$.

(68) Galan, U.; Lin, Y.; Ehlert, G. J.; Sodano, H. A. Effect of ZnO nanowire morphology on the interfacial strength of nanowire coated carbon fibers. Compos. Sci. Technol. 2011, 71, 946-954.

(69) Qian, H.; Greenhalgh, E. S.; Shaffer, M. S. P.; Bismarck, A. Carbon nanotube-based hierarchical composites: a review. J. Mater. Chem. 2010, 20, 4751.

(70) Williams, W. S.; Steffens, D. A.; Bacon, R. Bending Behavior and Tensile Strength of Carbon Fibers. J. Appl. Phys. 1970, 41, 48934901.

(71) Huang, X. Fabrication and Properties of Carbon Fibers. Materials 2009, 2, 2369-2403.

(72) Yao, J.; Yu, W. Tensile strength and its variation of PAN-based carbon fibers. I. Statistical distribution and volume dependence. $J$. Appl. Polym. Sci. 2006, 101, 3175-3182.

(73) Zhao, J.; Shaygan, M.; Eckert, J.; Meyyappan, M.; Rümmeli, M. H. A Growth Mechanism for Free-Standing Vertical Graphene. Nano Lett. 2014, 14, 3064-3071.

(74) Bo, Z.; Yang, Y.; Chen, J.; Yu, K.; Yan, J.; Cen, K. Plasmaenhanced chemical vapor deposition synthesis of vertically oriented graphene nanosheets. Nanoscale 2013, 5, 5180.

(75) Lv, P.; Feng, Y. Y.; Zhang, P.; Chen, H. M.; Zhao, N.; Feng, W. Increasing the interfacial strength in carbon fiber/epoxy composites by controlling the orientation and length of carbon nanotubes grown on the fibers. Carbon 2011, 49, 4665-4673.

(76) Lin, Y.; Ehlert, G.; Sodano, H. A. Increased interface strength in carbon fiber composites through a $\mathrm{ZnO}$ nanowire interphase. Adv. Funct. Mater. 2009, 19, 2654-2660.

(77) Krivchenko, V. A.; Maksimov, Y. M.; Podlovchenko, B. I.; Rakhimov, A. T.; Suetin, N. V.; Timofeev, M. A. Electrochemical activation of carbon nanowalls. Mendeleev Commun. 2011, 21, 264265.

(78) Choo, H.-S.; Kinumoto, T.; Nose, M.; Miyazaki, K.; Abe, T.; Ogumi, Z. Electrochemical oxidation of highly oriented pyrolytic graphite during potential cycling in sulfuric acid solution. J. Power Sources 2008, 185, 740-746.

(79) Xu, H.; Fan, X.; Lu, Y.; Zhong, L.; Kong, X.; Wang, J. Preparation of an electrochemically modified graphite electrode and its electrochemical performance for pseudo-capacitors in a sulfuric acid electrolyte. Carbon 2010, 48, 3300-3303.

(80) Fan, X.; Lu, Y.; Xu, H.; Kong, X.; Wang, J. J. Mater. Chem. 2011, 21, 18753. 